\title{
Solubility of Cyclodextrins and Drug/Cyclodextrin Complexes
}

\author{
Phennapha Saokham ${ }^{1,+}$, Chutimon Muankaew ${ }^{2,+}$, Phatsawee Jansook ${ }^{3,+}$ (iD \\ and Thorsteinn Loftsson ${ }^{4, * \text { (D) }}$ \\ 1 Faculty of Pharmacy, Rangsit University, Pathum Thani 12000, Thailand; phennapha.s@rsu.ac.th \\ 2 Faculty of Pharmacy, Siam University, 38 Petchkasem Road, Phasi Charoen District, \\ Bangkok 10160, Thailand; chutimon.mua@siam.edu \\ 3 Faculty of Pharmaceutical Sciences, Chulalongkorn University, 254 Phyathai Road, Pathumwan, \\ Bangkok 10330, Thailand; phatsawee.j@chula.ac.th \\ 4 Faculty of Pharmaceutical Sciences, University of Iceland, Hofsvallagata 53, 107 Reykjavik, Iceland \\ * Correspondence: thorstlo@hi.is; Tel.: +354-525-4464 \\ + These authors contributed equally to this work.
}

Academic Editor: Dr. Bernard Martel

Received: 13 April 2018; Accepted: 8 May 2018; Published: 11 May 2018

\begin{abstract}
Cyclodextrins (CDs), a group of oligosaccharides formed by glucose units bound together in a ring, show a promising ability to form complexes with drug molecules and improve their physicochemical properties without molecular modifications. The stoichiometry of drug/CD complexes is most frequently 1:1. However, natural CDs have a tendency to self-assemble and form aggregates in aqueous media. CD aggregation can limit their solubility. Through derivative formation, it is possible to enhance their solubility and complexation capacity, but this depends on the type of substituent and degree of substitution. Formation of water-soluble drug/CD complexes can increase drug permeation through biological membranes. To maximize drug permeation the amount of added $\mathrm{CD}$ into pharmaceutical preparation has to be optimized. However, solubility of CDs, especially that of natural CDs, is affected by the complex formation. The presence of pharmaceutical excipients, such as water-soluble polymers, preservatives, and surfactants, can influence the solubilizing abilities of CDs, but this depends on the excipients' physicochemical properties. The competitive CD complexation of drugs and excipients has to be considered during formulation studies.
\end{abstract}

Keywords: cyclodextrin; complex; solubility; poorly soluble drug

\section{Introduction}

Cyclodextrins (CDs) are cyclic oligosaccharides, formed by $\alpha-1,4$-linked glucose units, with a hydrophilic outer surface and a lipophilic central cavity [1-4]. $\alpha$-Cyclodextrin $(\alpha \mathrm{CD})$, $\beta$-cyclodextrin $(\beta C D)$, and $\gamma$-cyclodextrin $(\gamma C D)$ are natural products that can be found in small amounts in various fermented consumer products, such as beer. Although the unsubstituted natural $\alpha \mathrm{CD}, \beta C D$, and $\gamma \mathrm{CD}$, and their complexes, are hydrophilic their solubility in aqueous solutions is somewhat limited, especially that of $\beta C D$. Consequently the more soluble $\beta C D$ derivatives, such as 2-hydroxypropyl- $\beta C D$ (HP $\beta C D$ ) and sulfobutylether $\beta C D$ sodium salt (SBE $\beta C D)$, are preferred for use in aqueous pharmaceutical solutions, such as parenteral drug formulations, even though both $\alpha \mathrm{CD}$ and $\gamma \mathrm{CD}$ can be found at low concentrations in parenteral formulations [5]. Monographs for $\alpha \mathrm{CD}$, $\beta C D$, and $\gamma C D$ and two $\beta C D$ derivatives are in the European Pharmacopoeia and the United States Pharmacopeia/National Formulary (Table 1). CDs are included in over 40 marketed pharmaceutical products worldwide, in addition to numerous food, cosmetic, and toiletry products $[2,6,7]$. 
Table 1. Cyclodextrins with pharmacopoeia monographs.

\begin{tabular}{|c|c|c|c|c|c|}
\hline Cyclodextrin & $\mathbf{n}$ & $\mathbf{R}=\mathbf{H}$ or & Abbreviation & Synonyms & $\begin{array}{l}\text { Pharmacopoeia } \\
\text { Monographs }^{1}\end{array}$ \\
\hline$\alpha$-Cyclodextrin & 0 & & $\alpha \mathrm{CD}$ & alfadex & Ph.Eur., USP-NF, JPC \\
\hline$\beta$-Cyclodextrin & 1 & & $\beta C D$ & betadex & Ph.Eur., USP-NF, JPC \\
\hline 2-Hydroxypropyl- $\beta$-cyclodextrin & 1 & $-\mathrm{CH}_{2} \mathrm{CHOHCH}_{3}$ & $\mathrm{HP} \beta \mathrm{CD}$ & hydroxypropylbetadex & Ph.Eur., USP-NF \\
\hline $\begin{array}{c}\text { Sulfobutylether } \\
\beta \text {-cyclodextrin sodium }\end{array}$ & 1 & $-\left(\mathrm{CH}_{2}\right)_{4} \mathrm{SO}_{3}{ }^{-} \mathrm{Na}^{+}$ & $\mathrm{SBE} \beta \mathrm{CD}$ & $\begin{array}{l}\text { betadex sulfobutyl } \\
\text { ether sodium }\end{array}$ & USP-NF \\
\hline$\gamma$-Cyclodextrin & 2 & & $\gamma \mathrm{CD}$ & gammadex & Ph.Eur., USP-NF, JPC \\
\hline
\end{tabular}

${ }^{1}$ The European Pharmacopoeia (Ph.Eur.), the United States Pharmacopeia and the National Formulary (USP-NF), and the Japanese Pharmaceutical Codex (JPC).

Due to their ability to change physiochemical properties of drugs and other compounds, CDs are frequently referred to as enabling pharmaceutical excipients. CDs enable delivery of poorly water-soluble and chemically-unstable drugs to the body. Hence, CDs are able to convert biologically-active compounds that lack drug-like physiochemical properties into therapeutically-effective drugs. CDs (referred to as host molecules) are able to form inclusion complexes with drugs (referred to as guest molecules) by taking part of a drug molecule into the central CD cavity. This will change the physiochemical properties of the included drug. Formation of a drug/CD inclusion complex can, for example, increase the aqueous solubility of the drug, increase its chemical and physical stability, and enhance drug delivery through biological membranes. No covalent bonds are formed or broken during the complex formation and, in aqueous solutions, drug molecules bound within the CD inclusion complex are in dynamic equilibrium with free drug molecules (Figure 1) [8]. Drug molecules are readily released from the complex upon media dilution or by competitive complexation $[9,10]$. One or more drug molecules can form a complex with one $\mathrm{CD}$ molecule and one or more $\mathrm{CD}$ molecules can form a complex with one drug molecule. However, most commonly, one drug molecule (D) forms a complex with one $\mathrm{CD}$ molecule. The stoichiometry of the drug/CD complex $(\mathrm{D} / \mathrm{CD})$ is then 1:1 and the equilibrium constant $\left(\mathrm{K}_{1: 1}\right)$ defined as [11,12]:

$$
\mathrm{D}+\mathrm{CD} \stackrel{\mathrm{K}_{1: 1}}{\rightleftharpoons} \mathrm{D} / \mathrm{CD}
$$

The value of $\mathrm{K}_{1: 1}$ can be calculated by Equation (2) where $\mathrm{S}_{0}$ is the intrinsic solubility of the drug (i.e., the solubility in the aqueous media when no $C D$ is present), and Slope is the slope of the linear (i.e., $\mathrm{A}_{\mathrm{L}}$-type) drug-CD phase solubility diagram (Figure 2):

$$
\mathrm{K}_{1: 1}=\frac{\text { Slope }}{\mathrm{S}_{0} \cdot(1-\text { Slope })}
$$

However, the value of $K_{1: 1}$ is highly sensitive towards small changes in $\mathrm{S}_{0}$ and for poorly-soluble drugs it can be complicated to obtain accurate $S_{0}$ values. Furthermore, self-association of lipophilic drug molecules in aqueous media can lead to erroneous results. Under such conditions, it can be more accurate to determine the complexation efficacy $(\mathrm{CE})$ :

$$
\mathrm{CE}=\mathrm{K}_{1: 1} \cdot \mathrm{S}_{0}=\frac{\text { Slope }}{(1-\text { Slope })}
$$

Drug/CD complexes, especially those of the natural CDs, have tendency to self-assemble in aqueous solutions to form aggregates (Figure 1). At elevated CD concentrations these aggregates can become 
large and precipitate as solid microparticles [1]. In addition, the natural CDs and their complexes have limited solubility in aqueous solutions. These solubility limitations can give rise to characteristic B-type phase-solubility diagrams displayed in Figure 2 [11].

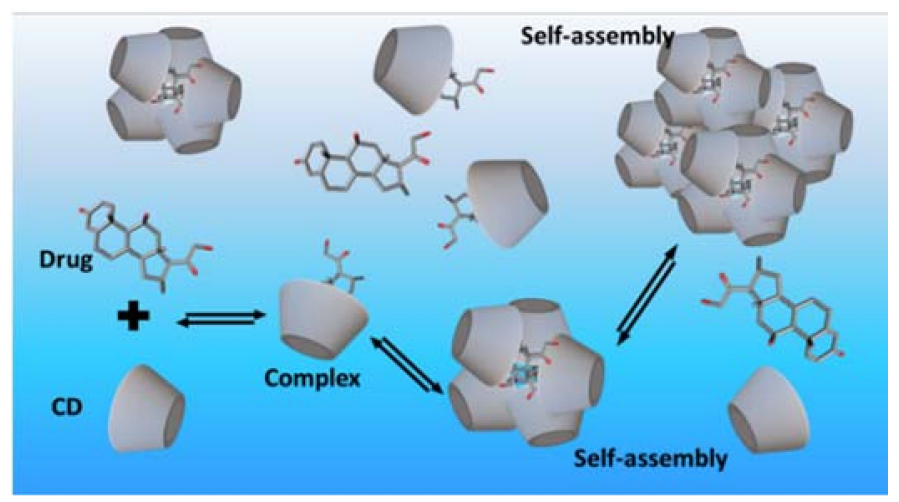

Figure 1. Formation of a cyclodextrin inclusion complex in an aqueous solution and self-assembly of cyclodextrin complexes.

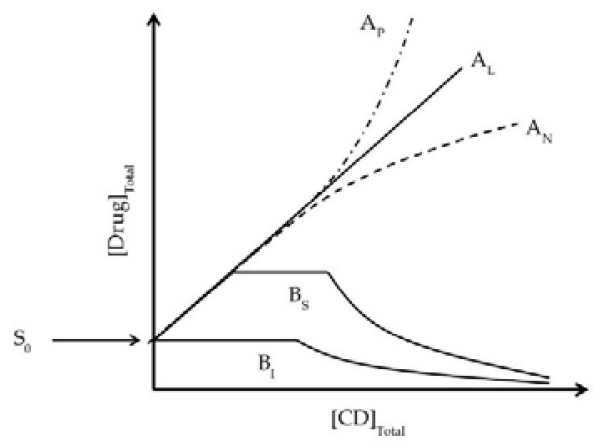

Figure 2. Types of phase-solubility diagrams according to Higuchi and Connors [11] showing how the total drug solubility changes with increasing CD concentration. A-type diagrams are formed when the drug/CD complex is soluble in the aqueous complexation media and they are usually associated with the water-soluble CD derivatives. B-type diagrams are observed when the complex has limited solubility in the media and these are usually associated with the natural CDs that have limited solubility in aqueous media. $A_{L}$ : linear diagram; $A_{P}$ : positive deviation from linearity; $A_{N}$ : negative deviation from linearity; $\mathrm{B}_{\mathrm{S}}$ : the complex has some but limited solubility; $\mathrm{B}_{\mathrm{I}}$ : the complex is insoluble.

The biopharmaceutical classification system (BCS) divides orally-administered drugs into four cases based on their solubility and intestinal permeability [13]. Drugs possessing favorable physiochemical properties are in Class I. They have adequate aqueous solubility and permeability to be well-absorbed from the gastrointestinal tract. In general, they gave good oral bioavailability. Drugs in Class II have inadequate aqueous solubility, but good permeability when in solution. Thus, their absorption from the gastrointestinal tract is slow and dissolution dependent. Drugs in Class III have adequate aqueous solubility but poor permeability, most often due to their very hydrophilic nature. Frequently such drugs are administered via parenteral injection. Finally, drugs in Class IV have both low aqueous solubility and are poorly absorbed from the gastrointestinal tract. Thus, they have very poor oral bioavailability and can be difficult to formulate as parenteral solutions. CDs can improve oral bioavailability of Class II drugs and sometimes also of Class IV drugs while they have negligible effect on Class III drugs and can under certain conditions even hamper absorption of some Class I drugs [10]. The BCS can be adapted to other types of dosage forms intended for non-oral administration [14]. Here the aqueous solubility of CDs and their complexes is reviewed, as well as the effect of CD concentrations on drug permeation through biological membranes. 


\section{Physiochemical Properties of Cyclodextrins}

The secondary hydroxyl groups on the CD molecule are located on the wider rim of the molecule and the primary hydroxyl groups on the narrow rim make them hydrophilic [12,15]. Due to their hydrophilic outer surface and their large number of hydrogen bond donors and acceptors, CDs have very negative $\log P_{o / w}$ value (i.e., the logarithmic value of the octanol/water partition coefficient) (Table 2) $[4,16]$. In aqueous solutions, $\mathrm{CDs}$ are susceptible to acid hydrolysis at low $\mathrm{pH}$ resulting in ring opening and formation of various linear oligosaccharides and glucose units, but they are stable under alkaline conditions. The hydroxyl groups attached to the rim start to deprotonate at $\mathrm{pH}$ about $12[17,18]$. Depending on the determination method and the location of the hydroxyl groups, the pKa values of the natural CDs have been reported to be between 12.1 and 13.5 [19]. The main difference of the three natural CDs, besides the size of their central cavity, is their aqueous solubility (Table 2). $\beta C D$ is the least soluble but, at the same time, possesses the most suitable cavity size for complex formation with many drugs [20,21]. The poor solubility can be explained in term of molecular rigidity of $\mathrm{CD}$ molecule, and the effect caused by the intermolecular hydrogen bonding in the crystal state [22,23]. Particularly, the hydrogen bond formation between neighboring $\mathrm{C} 2-\mathrm{OH}$ and $\mathrm{C} 3-\mathrm{OH}$ in the $\beta \mathrm{CD}$ molecule leads to the so-called complete secondary belt resulting in inflexible structure and reduced ability of the $\beta C D$ molecule to form intermolecular hydrogen bond with surrounding water molecules [15]. Molecular dynamic simulations have shown high water density and strong ordering of water molecules around the $\beta C D$ molecule $[24,25]$. This indicates that water molecules surrounding dissolved $\beta C D$ molecules have unfavorable enthalpy and low entropy, which can explain the low water solubility of $\beta C D$ compared to other natural CDs. In contrast, $\alpha C D$ has incomplete belt of hydrogen bonds and $\gamma \mathrm{CD}$ has non-coplanar structure. Consequently, both $\alpha \mathrm{CD}$ and $\gamma \mathrm{CD}$ possess higher solubility in water.

To enhance solubilizing potential of the natural CDs, including their complexation capacity, $\mathrm{CD}$ derivatives have been prepared by reacting the secondary and/or primary $\mathrm{OH}$ groups of the molecule with a wide variety of substituents [26,27]. Randomly methylated and hydroxypropylated CDs and sulfobutylether CDs are manufactured on an industrial scale and often used in pharmaceutical products, whereas other $\mathrm{CD}$ derivatives are utilized for specific purposes, such as the removal of pollutants from the environment and reagents for drug analysis [28,29]. Attachment of these substituents disrupts the regular hydrogen bonding network within native $C D$ molecule increasing their ability to interact with the surrounding water molecules [30]. The result can be over 100-fold increase in their aqueous solubility [31-34]. For example, the sulfobutylether $\beta C D$ anionic alkyl chains form an extremely hydrophilic exterior surface. These anionic chains provide for electrostatic repulsion resulting in extension of the hydrophobic central cavity and thereby intensifying its solubilizing potential [35]. Most frequently, modified natural CDs exist in amorphous isomeric mixtures of various degree of substitution (DS). The DS has a great influence on the physicochemical properties of CDs and their ability to form complexes. For instance, randomly-methylated $\beta C D(R M \beta C D)$ has the highest solubility in water when the degree of substitution is about 14 , that is, when two-thirds of the $\mathrm{OH}$-groups have been replaced by methoxy groups [36]. Increasing the DS above 14 decreases the RM $\beta C D$ solubility. The cavity diameter of CD derivatives is similar to their parent CDs. However, an effect of substituent location on the cavity volume has been observed [37]. It has been observed that the hydroxypropylation of $\mathrm{OH}$ groups at the O-2 position results in a more spread out configuration, whereas the substitution of $\mathrm{OH}$ groups at the O-6 position reduces the water density inside the $\mathrm{CD}$ cavity $[30,38,39]$. Unlike native $\mathrm{CDs}$ that have negligible surface activity, some $\mathrm{CD}$ derivatives manifest such behavior. It is reported that methylated and hydroxyalkylated CD molecules reduce the surface tension of water $[40,41]$. The increase in surface activity is proportional to the increased degree of substitution. On the other hand, derivatives with polar ionic groups, such as carboxylate ion and sulfobutyl groups, have no influence on surface activity [35]. Table 2 lists dimensional structures and physicochemical properties of the three most common natural CDs and some of their more common derivatives. 
Table 2. The cavity size and some important physicochemical properties of natural CDs and some of their derivatives.

\begin{tabular}{|c|c|c|c|c|c|c|c|c|c|}
\hline Types & Substituent & ${ }^{1}$ DS & $\begin{array}{l}\text { Inner Cavity } \\
\text { Diameter (Å) }\end{array}$ & $\begin{array}{c}\text { Hydrogen } \\
\text { Donors }\end{array}$ & $\begin{array}{l}\text { Hydrogen } \\
\text { Acceptors }\end{array}$ & $\begin{array}{c}\text { Solubility } \\
\left(\mathrm{mg} / \mathrm{mL}, 25^{\circ} \mathrm{C}\right)\end{array}$ & $\begin{array}{l}\text { Log } \\
\mathbf{P}_{o / w} \\
\end{array}$ & $\begin{array}{l}\text { Surface Tension } \\
\quad(\mathrm{mN} / \mathrm{m})\end{array}$ & References \\
\hline \multicolumn{10}{|l|}{ Naural CD } \\
\hline$\alpha \mathrm{CD}$ & $\mathrm{H}$ & 0 & $4.7-5.3$ & 18 & 30 & 145 & -13 & 71 & {$[1,42]$} \\
\hline$\beta C D$ & $\mathrm{H}$ & 0 & $6.0-6.5$ & 21 & 35 & 18.5 & -14 & 71 & [1] \\
\hline$\gamma \mathrm{CD}$ & $\mathrm{H}$ & 0 & $7.5-8.3$ & 24 & 40 & 232 & -17 & 71 & [1] \\
\hline \multicolumn{10}{|l|}{ Modified CD } \\
\hline $\mathrm{HP} \alpha \mathrm{CD}$ & $-\mathrm{CH}_{2}-\mathrm{CHOH}-\mathrm{CH}_{3}$ & 3.6 & $4.5-5.3$ & 18 & 36 & - & - & - & [43] \\
\hline $\mathrm{CM} \beta \mathrm{CD}$ & $-\mathrm{CH}_{2}-\mathrm{CO}_{2} \mathrm{H}$ & $3-5$ & - & 21 & 49 & 50 & -4.9 & - & [32] \\
\hline $\mathrm{DM} \beta \mathrm{CD}$ & $-\mathrm{CH}_{3}$ & $12-16$ & $5.8-6.5$ & 7 & 35 & 570 & - & 62 & [34] \\
\hline $\mathrm{RM} \beta \mathrm{CD}$ & $-\mathrm{CH}_{3}$ & $9.7-13.6$ & - & 9 & 35 & $>500$ & -6 & $57.5-54.1$ & {$[1,44,45]$} \\
\hline $\mathrm{TM} \beta C D$ & $-\mathrm{CH}_{3}$ & 21 & $4-7$ & 0 & 35 & 310 & - & 56 & {$[34,46]$} \\
\hline HE $\beta C D$ & $-\mathrm{CH}_{2}-\mathrm{CH}_{2} \mathrm{OH}$ & 3.6 & - & 21 & 42 & $>2000$ & - & - & {$[26,47]$} \\
\hline $\mathrm{HP} \beta \mathrm{CD}$ & $-\mathrm{CH}_{2}-\mathrm{CHOH}-\mathrm{CH}_{3}$ & $2.8-10.5$ & 6.0 & 25 & 39 & $>1200$ & -11 & $54.8-57.5$ & {$[1,47]$} \\
\hline SBE $\beta C D$ & $\left(\mathrm{CH}_{2}\right)_{4}-\mathrm{SO}_{3} \mathrm{Na}$ & $6.2-6.9$ & - & 21 & 35 & $>1200$ & $<-10$ & 71 & [1] \\
\hline $\mathrm{HP} \gamma \mathrm{CD}$ & $-\mathrm{CH}_{2}-\mathrm{CHOH}-\mathrm{CH}_{3}$ & $3.0-5.4$ & 8.0 & 24 & 45 & 800 & -13 & - & [1] \\
\hline SBE $\gamma C D$ & $\left(\mathrm{CH}_{2}\right)_{4}-\mathrm{SO}_{3} \mathrm{Na}$ & 4-8 & - & - & - & - & - & - & {$[43,48]$} \\
\hline SUG & $-\mathrm{SCH}_{2} \mathrm{CH}_{2} \mathrm{CO}_{2} \mathrm{Na}$ & 8 & $7.5-8.3$ & 24 & 48 & Very soluble & -16 & 72.2 & [1] \\
\hline \multicolumn{10}{|l|}{ Branched CD } \\
\hline $\mathrm{G}_{1} \beta \mathrm{CD}$ & glucosyl & 1 & $6.0-6.5$ & 24 & 40 & 970 & -9 & 71 & {$[26,49]$} \\
\hline $\mathrm{G}_{2} \beta C D$ & maltosyl & 1 & - & 27 & 45 & $>1500$ & -9 & 72 & [33] \\
\hline GUG $\beta C D$ & glucoronylglucosyl & 1 & - & - & - & $>2000$ & - & 73 & [33] \\
\hline
\end{tabular}




\section{How Much Solubilization Is Needed?}

CDs can both enhance and hamper drug permeation through biological membranes. Although active drug transport through biological membranes does exist, drug molecules are mainly transported via passive diffusion through the membranes. In general, the driving force for passive diffusion through an aqueous environment (e.g., mucus) into and through membranes, such as mucosa is not the concentration gradient but the gradient of chemical potential, which is a continuous function across interfaces [50]. Likewise, the partitioning of drug molecules from a membrane exterior into the outermost membrane layer is controlled by the chemical potential. Thus, maximum drug permeation from an aqueous exterior into and through biological membrane is expected to be obtained when the drug is at its highest thermodynamic potential [50]. In other words, maximum drug permeation is obtained when the aqueous membrane exterior is saturated with the drug [51]. However, the amount of drug permeating through a membrane also depends on the concentration of dissolved drug at the membrane exterior. Figure 3 shows the flux of hydrocortisone through hairless mouse skin in vitro. The skin was mounted in a Franz diffusion cell where the donor phase was unstirred (i.e., consisted of an unstirred diffusion layer), but the receptor phase was stirred. The total amount of hydrocortisone (i.e., dissolved and undissolved) in the donor phase was kept constant at $16 \mathrm{mg} / \mathrm{mL}$ while the CD concentration was increased from 0 to $20 \%(w / v)$. About $8 \%(w / v)$ $\mathrm{CD}$ was needed to solubilize $16 \mathrm{mg}$ of hydrocortisone in $1 \mathrm{~mL}$ of the donor phase (i.e., the aqueous medium). Thus, increasing the CD concentration from 0 to $8 \%(w / v)$ increases the amount of dissolved drug in the donor phase. At these CD concentrations, the donor phase was always saturated with the drug and, thus, the drug is always at its maximum thermodynamic potential. Under these conditions, the drug molecules have maximum tendency to leave the donor phase and partition into the skin. However, only dissolved drug molecules can partition into the skin and, thus, increasing the concentration of dissolved drug molecules through formation of water-soluble drug/CD complexes increases the number of drug molecules that are able to partition into the skin and then permeate through the skin into the receptor phase. Increasing the $\mathrm{CD}$ concentration beyond $8 \%(w / v)$ decreases the thermodynamic potential of the drug. The solubility of hydrocortisone in $10 \%(w / v)$ CD solution is about $20 \mathrm{mg} / \mathrm{mL}$ and about $26 \mathrm{mg} / \mathrm{mL}$ at $13 \%(w / v) \mathrm{CD}$. The donor phase was no longer saturated with the drug and the drug molecules have decreased tendency to leave the donor phase and partition into the membrane. To ensure maximum drug permeation through biological membranes one should only add just enough $C D$ to the pharmaceutical formulation to solubilize the entire drug dose. Too little or too much $\mathrm{CD}$ will result in less than optimum drug flux through the membrane. However, small excess CD has to be included in aqueous drug solutions to prevent drug precipitation during storage and handling.

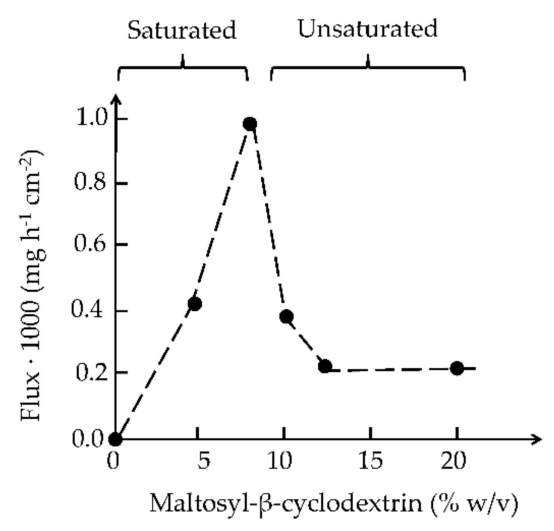

Figure 3. The effect of maltosyl- $\beta$-cyclodextrin concentration on the permeation of hydrocortisone through hairless mouse skin in vitro. The amount of hydrocortisone in the aqueous donor medium was kept constant $16 \mathrm{mg} / \mathrm{mL}$ but the maltosyl- $\beta$-cyclodextrin concentration was from 0 to $20 \%$ $(w / v)$. Below $8 \%(w / v)$ maltosyl- $\beta$-cyclodextrin the medium was hydrocortisone suspension in water, but hydrocortisone solution in water at higher concentrations. Based on unpublished results. 
In solid dosage forms such as tablets adequate amount of $C D$ should be included to prevent dissolution controlled drug absorption from the gastrointestinal tract [10]. Excess CD can hamper absorption from the gastrointestinal tract and, for example, $\alpha \mathrm{CD}$ is used to bind and prevent absorption of dietary fat [52]. The unsubstituted natural $\alpha \mathrm{CD}, \beta C D$, and $\gamma \mathrm{CD}$ frequently form drug/CD complexes that have limited solubility in water. However, their solubility is most often sufficient to prevent dissolution limited absorption, and since natural CDs have lower molecular weight than their more water-soluble derivatives their formulation bulk will be lower. General observations regarding the amount of $\mathrm{CD}$ to be included in pharmaceutical formulations are listed in Table 3.

Table 3. In general, pharmaceutical formulations should contain sufficient CD to solubilize the entire drug dose. However, how much solubilization is needed will depend on the formulation.

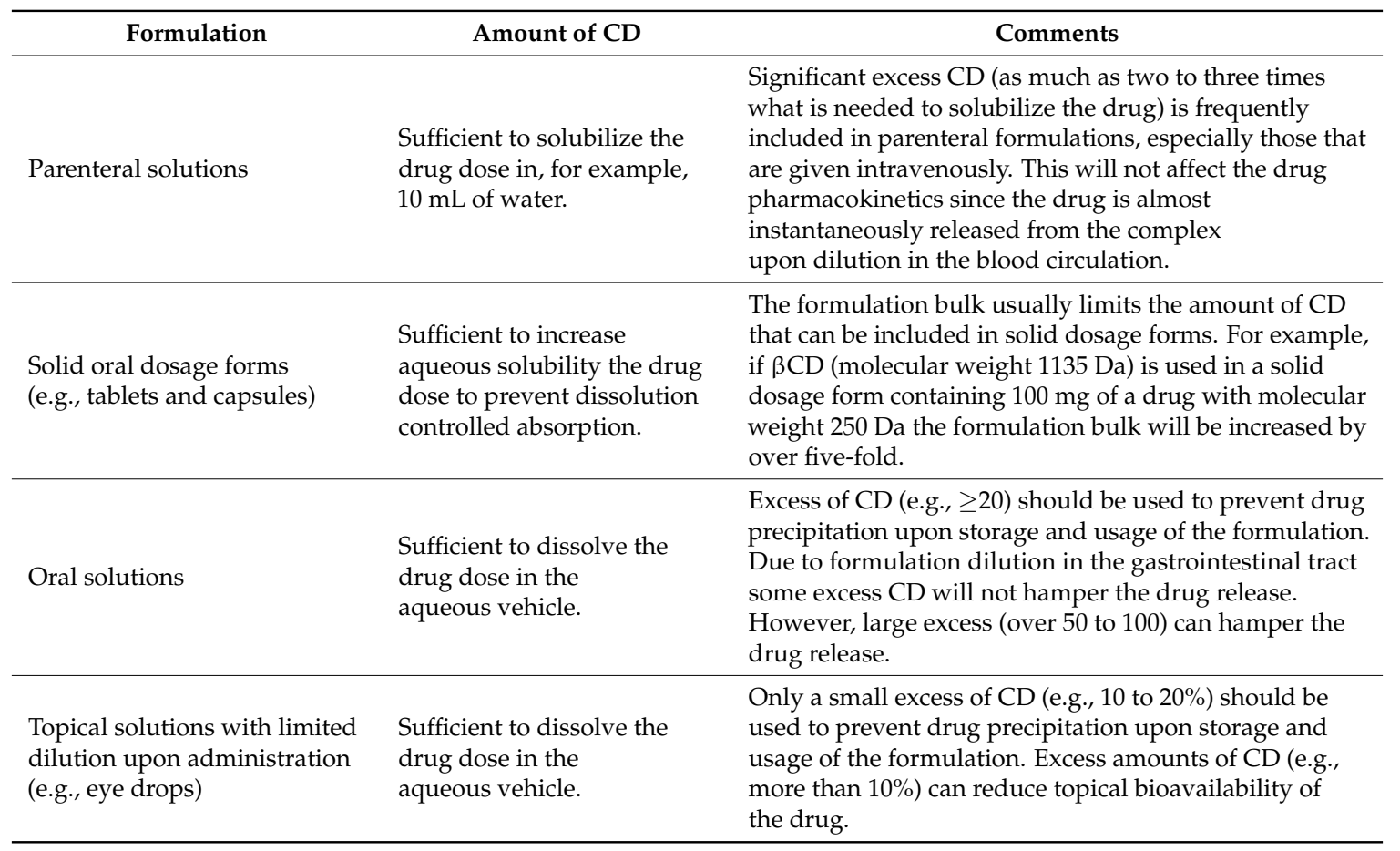

\section{The Effect of the Guest Molecule on the Cyclodextrin Solubility}

Not only are aqueous solubilities of drugs affected by the formation of drug/CD complexes, but also that of the CDs themselves. According to the phase-solubility diagram classification system that was introduced by Higuchi and Connors [11], linear $A_{L}$-type diagrams show that the total drug solubility increases as a function of $C D$ concentration through formation of soluble drug/CD complexes. If one molecule of drug forms a complex with one molecule of $C D$, the slope of a straight line is less than unity and the value of $K_{1: 1}$ can be calculated by applying Equation (2). $A_{P}$ - or $A_{N^{-}}$-type phase-solubility diagrams (i.e., displaying positive or negative deviation from linearity, respectively) suggest formations of higher-order drug/CD complexes [20,53]. If the slope of a linear diagram is greater than unity, but less than 2, the complex formed is likely to be of second, or higher, order with respect to the drug, but first-order with respect to $\mathrm{CD}$. For example, a $\mathrm{K}_{2: 1}$ value of drug/CD complex can be determined by [46]:

$$
\mathrm{K}_{2: 1}=\frac{\text { slope }}{(2-\text { slope }) \mathrm{S}_{0}^{2}}
$$

The A $A_{P}$-type phase-solubility diagram suggests the formation of higher-order complexes with respect to $\mathrm{CD}$ (e.g., formation of 1:2 drug/CD complex). The complex stoichiometry and equilibrium constant $\left(\mathrm{K}_{2: 1}\right)$ can then be determined by fitting the solubility results to a quadratic model [20,54]. The tendency of a given drug and CD to form a complex is expressed by a stability constant for the complex $\left(\mathrm{K}_{\mathrm{m}: n}\right)$, 
where $\mathrm{m}$ and $\mathrm{n}$ are the number of molecules of the drug and CD forming the complex, respectively, or the equilibrium binding constant $\left(\mathrm{K}_{\mathrm{a}}\right)$ defined by the ratio of association $\left(\mathrm{k}_{\mathrm{a}}\right)$ and dissociation $\left(\mathrm{k}_{\mathrm{d}}\right)$ rate constants [55,56]. The $\mathrm{K}_{\mathrm{a}}$ values of most drug/CD complexes are less than $10^{5} \mathrm{M}^{-1}$, indicating that the drug and CD interactions are relatively weak [20,56]. Moreover the forward $\left(k_{a}\right)$ and reverse $\left(k_{d}\right)$ reactions are very fast and the relaxation time is short (less than $1 \mathrm{~s}$ ) [55,57], indicating that drug and CD molecules in complex are in rapid equilibrium with free molecules in the solution. Thus, in aqueous solutions drug/CD complexes are in dynamic equilibrium with free drug and CD molecules. Studies of dissolved $\gamma$ CD in aqueous complexation media of indomethacin $/ \gamma C D$, diclofenac sodium $/ \gamma C D$, and amphotericin $B / \gamma C D$ (all of which display $A_{L}$-type phase-solubility diagrams) show that the determined concentrations of $\gamma C D$ are almost identical to the initial concentration of dissolved $\gamma \mathrm{CD}$ before the addition of the drug [58]. The influence of drug concentration on CD solubility in complexation media is negligible when the phase-solubility diagram of the drug/CD complex presents as A-type (Figure 4a).

In general, the water-soluble CD derivatives form A-type phase-solubility diagrams, whereas the B-type diagrams are mainly observed when the natural CDs form complexes with poorly-soluble drugs [20]. The B-type phase-solubility diagrams indicate the formation of complexes with limited solubility in the complexation media. The initial linear region of $\mathrm{B}_{\mathrm{S}}$-type diagrams can be regarded as $\mathrm{A}_{\mathrm{L}}$-type diagrams. In this region of the diagrams drug molecules do not affect the CD solubility. In the plateau region of the B-type diagram the drug solubility is constant even when the CD concentration is increased, indicating the formation of drug/CD complexes with limited solubility and that the CD solubility is depressed by the presence of the drug [58,59]. The amount of dissolved CD and drug in aqueous complexation media are constant through the length of plateau region (Figure 4b) [59,60]. However, the amounts of drug and $\mathrm{CD}$ in the precipitate can differ. Schönbeck reports that precipitate obtained from phase-solubility studies consists of solid drug (i.e., hydrocortisone in excess) and precipitated drug $/ \gamma$ CD complex. The ratio of $\gamma \mathrm{CD}$ to drug in precipitate increases as a function of the $\gamma \mathrm{CD}$ concentration (i.e., the amount of precipitated drug decreases, whereas the amount of precipitated drug $/ \gamma$ CD complex increases) indicating that the stoichiometry of the drug/CD inclusion complex gradually changes from 1:1 to higher-order drug/CD complexes [61]. Since the solubility of the drug/CD complex is limited, higher-order drug/CD complexes precipitate resulting in decreased CD solubility in the aqueous complexation media. The descendent region of B-type phase-solubility diagrams show that solubility of the drug decreases when the concentration of $\mathrm{CD}$ increases, indicating that CD preferably forms self-assembled aggregates and the solubility of CD gradually increases even in the presence of the drug [60]. The absence of solid pure drug in the precipitate from phase-solubility studies also indicates that only higher-order drug/CD complexes are being formed [61]. In conclusion, the CD solubility, especially that of the natural CDs, can be decreased in the presence of drugs if high-order drug/CD complexes, for example 1:2 or 2:1, are formed and then precipitated from the media.

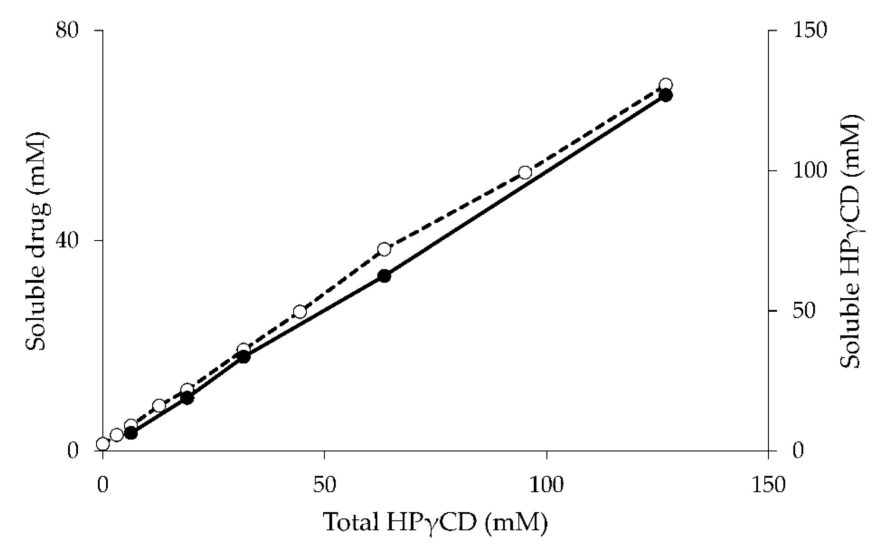

(a)

Figure 4. Cont. 


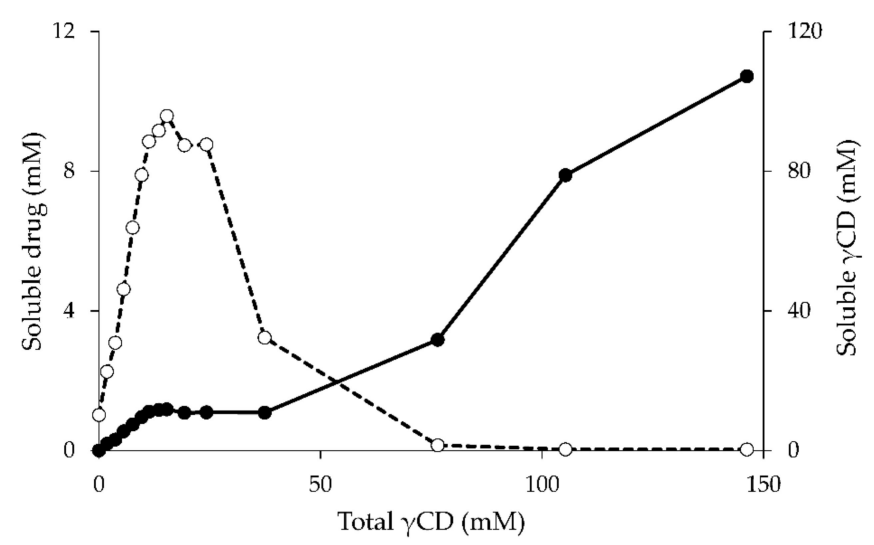

(b)

Figure 4. The phase-solubility diagram of hydrocortisone/ $\mathrm{HP} \gamma \mathrm{CD}$ (a) [58] and hydrocortisone $/ \gamma \mathrm{CD}$ (b) [59] complex. Concentrations of the soluble drug (open circle) and CD (filled circle) are plotted against the concentration of total CD.

\section{Excipients and Cyclodextrin Solubility}

In pharmaceutical products, not only drugs and CDs are present as drug/CD complexes, but also various excipients, such as antioxidants, antimicrobial agents, surfactants and polymers. These excipients can enhance or hamper the CD solubilization of drugs, as shown in Table 4. Preservatives, such as propyl- and methylparaben, can compete with drug molecules and expel them from the $C D$ cavities and, thus, reduce $C D$ solubilization of the drugs [62,63]. In addition, $\mathrm{CD}$ complexation of the preservatives can reduce their antimicrobial efficacy. Therefore, formulation scientists need to adjust the amount of preservative in CD-containing formulations to obtain the desired preservative efficacy and safety [64]. The additive or synergistic effects of excipients on the drug solubility through CD inclusion complexes have been reviewed [20,65]. Various additives that are commonly used in pharmaceutical formulations, such as organic acids or bases, organic salts (counterions), cosolvents, metal ions, and water-soluble polymers, can increase the complexation efficacy (CE) of CDs via stabilization and solubilization of drug/CD nanoparticles. Recently, we have shown that $\mathrm{CDs}$ and drug/CD complexes can self-assemble and form complex aggregates in aqueous solutions, which can enhance the drug solubility $[54,66,67]$. Water-soluble polymers play an important role in the stabilization of aggregates. Formation of ternary drug:CD:polymer complexes can be promoted by heating the media, for example, in an autoclave $\left(121^{\circ} \mathrm{C}\right.$ for $\left.15-20 \mathrm{~min}\right)$ or in an ultrasonic bath (e.g., $60-70^{\circ} \mathrm{C}$ for $1 \mathrm{~h}$ ) [68]. It has been shown that the addition of small amounts of water-soluble polymer reduces the formulation bulk, decreasing the manufacturing cost and increasing the possibility of using CDs as solubilizers in various solid dosage forms. For instance, the amount of $\beta C D$ or SBE $\beta C D$ required to solubilize $3.0 \mathrm{mg}$ of glibenclamide were $300 \mathrm{mg}$ and $1200 \mathrm{mg}$, respectively. Addition of hydroxypropyl methylcellulose (HPMC) to the binary complexes reduced the amount of CD in the formulation to $120 \mathrm{mg}$ and $250 \mathrm{mg}$, respectively [69].

The excipients in the pharmaceutical formulations containing $C D$ may increase or decrease the ability of $\mathrm{CD}$ to solubilize drugs depending on their nature and physicochemical properties. Thus, the exact amount of CD needed in a given formulation should be determined by studies (e.g., phase-solubility studies) in a medium which composition is close to that of the final formulation. The competitive complexation effect of the secondary drug should also be considered [70]. 
Table 4. Effects of some pharmaceutical excipients on the cyclodextrin solubilization.

\begin{tabular}{|c|c|c|c|c|}
\hline Excipients & Examples & Effect on Complexation Enhancement & Some Brief Observations & References \\
\hline \multirow{3}{*}{$\begin{array}{l}\text { Acids, bases, } \\
\text { inorganic/organic salts }\end{array}$} & \multirow{3}{*}{$\begin{array}{l}\text { hydrochloride, citrate, } \\
\text { aspartate, mesylate, maleate, } \\
\text { tartrate, phosphate, acetate }\end{array}$} & \multirow{3}{*}{$\begin{array}{l}\text { Increase intrinsic solubility of drugs }\left(\mathrm{S}_{0}\right) \\
\text { and/or the apparent stability constant }\left(\mathrm{K}_{1: 1}\right) \\
\text { resulting in increased CE }\end{array}$} & $\begin{array}{l}\text { Salt formation of ziprasidone mesylate enhance the } C E \text { of drug up to } 100 \\
\text { and } 240 \text { times in aqueous } H P \beta C D \text { and SBE } \beta C D \text { solutions when compared } \\
\text { with the free base of drug }\end{array}$ & [71] \\
\hline & & & $\begin{array}{l}\text { Ternary complex of terfenadine } / \beta C D / \text { inorganic acid (phosphate, citrate) } \\
\text { induce the synergistic effect of } C D \text { solubilization }\end{array}$ & [72] \\
\hline & & & $\begin{array}{l}\text { The addition of sodium acetate into the complexing medium containing } \beta C D \\
\text { could increase hydrocortisone solubility up to } 220 \%\end{array}$ & [73] \\
\hline \multirow{3}{*}{ Cosolvents } & \multirow{3}{*}{ ethanol, propylene glycol (PG) } & \multirow[t]{2}{*}{ Enhance $S_{0}$ but in most cases decrease $K_{1: 1}$} & $\begin{array}{l}\mathrm{K}_{1: 1} \text { of fluasterone/HP } \beta C D \text { complex decreases with increasing ethanol } \\
\text { concentration but the drug solubility increased at high ethanol } \\
\text { concentration }(>40 \% v / v)\end{array}$ & [74] \\
\hline & & & $\begin{array}{l}\text { Ternary complex of diazepam } / \mathrm{PG} / \beta C D \text { increased the diazepam solubility } \\
\text { than that of the mixture of } \mathrm{PG} \text { and water }\end{array}$ & [75] \\
\hline & & $\begin{array}{l}\text { Hamper complexation by the } \\
\text { competitive effect }\end{array}$ & $\begin{array}{l}\text { At higher concentrations of PG, the methyltestosterone solubility in } \\
\text { presence of } H P \beta C D \text { decreased possibly due to the complex dissociation }\end{array}$ & [76] \\
\hline Water-soluble polymers & HPMC, Na CMC, PVA, PVP & $\begin{array}{l}\text { Formation of ternary complex } \\
\text { (drug/CD/polymer) that can increase } K_{1: 1}\end{array}$ & $\begin{array}{l}\text { Polymers and CDs can form water-soluble complexes with poorly } \\
\text { water-soluble drugs, for example, acetazolamide, carbamazepine } \\
\text { hydrocortisone, naproxen, pregnenolone, tropicamide, etc. have been reviewed } \\
\text { Synergistic solubilization effect is possible through micellar-like solubilization } \\
\text { or stabilization of self-assembled CD and/or CD complex aggregates }\end{array}$ & {$[20,77-79]$} \\
\hline Metal ions & $\mathrm{Mg}^{2+}$ & $\begin{array}{l}\text { Enhance } \mathrm{CE} \text { by increasing } \mathrm{S}_{0} \text { via formation } \\
\text { of drug/CD/metal ion complexes }\end{array}$ & $\begin{array}{l}\text { Synergistic solubilization of quinolone was obtained when the addition of } \mathrm{Mg}^{2+} \\
\text { to the drug/HP } \beta C D \text { complexes }\end{array}$ & [80] \\
\hline
\end{tabular}

Hydroxypropyl methylcellulose (HPMC); sodium carboxymethylcellulose (Na CMC); polyvinyl alcohol (PVA), polyvinyl pyrrolidone (PVP). 


\section{Conclusions and Directions}

Various physiochemical properties of drugs can be altered through CD complexation, especially drug solubility in aqueous biological media. In aqueous media, drug molecules of appropriate size and structure will enter into the central cavity of CD molecules to form water-soluble complexes and, frequently, enhanced total drug solubility is observed. $A_{L}$-type phase solubility diagrams represent linear relationships between concentrations of dissolved drug and amounts of $C D$ added to an aqueous medium. However, when B-type diagrams are observed, the CD molecules and their complexes self-assemble to form aggregates that possess limited solubility. While drug/CD complexes are in dynamic equilibrium with free drug and CD molecules in aqueous media, CD aggregates frequently precipitate from the media. The solid CD aggregates decrease CD solubility and this will, again, influence formation of drug/CD complexes. Pharmaceutical excipients, for example water-soluble polymers, are able to hamper this type of CD precipitation via formation of ternary complexes leading to enhanced CD complexation efficacy. Since CD forms complexes with wide variety of guest molecules, including drugs and pharmaceutical excipients, competitive complexation should always be take into account. Therefore, the amount of $C D$ and the type and composition of pharmaceutical excipients used in pharmaceutical formulation needs to be carefully selected.

Funding: This research received no external funding.

Conflicts of Interest: The authors declare no conflict of interest.

\section{Abbreviations}

The following abbreviations are used in this manuscript:

$\begin{array}{ll}\text { CD } & \text { Cyclodextrin } \\ \text { CE } & \text { Complexation efficiency } \\ \text { CM } \beta C D & \text { Carboxymethyl- } \beta C D \\ \text { DM } \beta C D & \text { Dimethyl- } \beta C D \\ \text { DM } \alpha C D & \text { Dimethyl- } \alpha \text { CD } \\ \text { DM } \gamma C D & \text { Dimethyl- } \gamma \text { CD } \\ \text { DS } & \text { Degree of substitution } \\ \text { G1 } \beta C D & \text { Glucosyl- } \beta C D \\ \text { G2 } \beta C D & \text { Maltosyl- } \beta C D \\ \text { GUG } \beta C D & \text { Glucoronyl-glucosyl- } \beta C D \\ \text { HE } \beta C D & \text { Hydroxyethyl- } \beta C D \\ \text { HPMC } & \text { Hydroxypropyl methylcellulose } \\ \text { HP } \alpha C D & \text { 2-hydroxypropyl- } \alpha \text { CD } \\ \text { HP } \gamma C D & \text { Hydroxypropyl- } \gamma C D \\ \text { NaCMC } & \text { Sodium carboxymethylcellulose } \\ \text { PVA } & \text { Polyvinyl alcohol } \\ \text { PVP } & \text { Polyvinyl pyrrolidone } \\ \text { SBE } \gamma C D & \text { Sulfobutylether- } \gamma C D \\ \text { SUG } & \text { Sugammadex } \\ \text { TM } \beta C D & \text { Trimethyl- } \beta C D \\ \text { TM } \alpha C D & \text { Trimethyl- } \alpha C D \\ \text { TM } \gamma C D & \text { Trimethyl- } \gamma C D \\ \alpha C D & \alpha \text {-Cyclodextrin } \\ \beta C D & \beta \text {-Cyclodextrin } \\ \gamma C D & \gamma \text {-Cyclodextrin } \\ & \end{array}$




\section{References}

1. Jansook, P.; Ogawa, N.; Loftsson, T. Cyclodextrins: Structure, physicochemical properties and pharmaceutical applications. Int. J. Pharm. 2018, 535, 272-284. [CrossRef] [PubMed]

2. Astray, G.; Gonzalez-Barreiro, C.; Mejuto, J.C.; Rial-Otero, R.; Simal-Gándara, J. A review on the use of cyclodextrins in foods. Food Hydrocoll. 2009, 23, 1631-1640. [CrossRef]

3. Muankaew, C.; Loftsson, T. Cyclodextrin-based formulations: A non-invasive platform for targeted drug delivery. Basic Clin. Pharmacol. Toxicol. 2018, 122, 46-55. [CrossRef] [PubMed]

4. Kurkov, S.V.; Loftsson, T. Cyclodextrins. Int. J. Pharm. 2013, 453, 167-180. [CrossRef] [PubMed]

5. FDA, U.S.F.D.U.S. Inactive Ingredient Search for Approved Drug Prodructs. Availabe online: https://www.accessdata. fda.gov/scripts/cder/iig/getiigWEB.cfm (accessed on 1 April 2018 ).

6. Arima, H.; Motoyama, K.; Higashi, T. Potential use of cyclodextrins as drug carriers and active pharmaceutical ingredients. Chem. Pharm. Bull. 2017, 65, 341-348. [CrossRef] [PubMed]

7. Hu, Q.-D.; Tang, G.-P.; Chu, P.K. Cyclodextrin-based host-guest supramolecular nanoparticles for delivery: From design to applications. Acc. Chem. Res. 2014, 47, 2017-2025. [CrossRef] [PubMed]

8. Stella, V.J.; Rao, V.M.; Zannou, E.A.; Zia, V. Mechanisms of drug release from cyclodextrin complexes. Adv. Drug Del. Rev. 1999, 36, 3-16. [CrossRef]

9. Kurkov, S.V.; Madden, D.E.; Carr, D.; Loftsson, T. The effect of parenterally administered cyclodextrins on the pharmacokinetics of coadministered drugs. J. Pharm. Sci. 2012, 101, 4402-4408. [CrossRef] [PubMed]

10. Loftsson, T.; Moya-Ortega, M.D.; Alvarez-Lorenzo, C.; Concheiro, A. Pharmacokinetics of cyclodextrins and drugs after oral and parenteral administration of drug/cyclodextrin complexes. J. Pharm. Pharmacol. 2016, 68, 544-555. [CrossRef] [PubMed]

11. Higuchi, T.; Connors, K.A. Phase-solubility techniques. Adv. Anal. Chem. Instrum. 1965, 4, 117-212.

12. Brewster, M.E.; Loftsson, T. Cyclodextrins as pharmaceutical solubilizers. Adv. Drug Del. Rev. 2007, 59, 645-666. [CrossRef] [PubMed]

13. Amidon, G.L.; Lennernas, H.; Shah, V.P.; Crison, J.R. A theoretical basis for a biopharmaceutic drug classification: The correlation of in vitro drug product dissolution and in vivo bioavailability. Pharm. Res. 1995, 12, 413-420. [CrossRef] [PubMed]

14. Loftsson, T. Cyclodextrins and the biopharmaceutics classification system of drugs. J. Incl. Phenom. Macrocycl. Chem. 2002, 44, 63-67. [CrossRef]

15. Szejtli, J. Introduction and general overview of cyclodextrin chemistry. Chem. Rev. 1998, 98, $1743-1754$. [CrossRef] [PubMed]

16. Loftsson, T.; Vogensen, S.B.; Brewster, M.E.; Konráðsdóttir, F. Effects of cyclodextrins on drug delivery through biological membranes. J. Pharm. Sci. 2007, 96, 2532-2546. [CrossRef] [PubMed]

17. Kondo, H.; Nakatani, H.; Hiromi, K. In vitro action of human and porcine $\alpha$-amylases on cyclomalto-oligosaccharides. Carbohydr. Res. 1990, 204, 207-213. [CrossRef]

18. Lumholdt, L.R.; Holm, R.; Jørgensen, E.B.; Larsen, K.L. In vitro investigations of $\alpha$-amylase mediated hydrolysis of cyclodextrins in the presence of ibuprofen, flurbiprofen, or benzo[a]pyrene. Carbohydr. Res. 2012, 362, 56-61. [CrossRef] [PubMed]

19. Gaidamauskas, E.; Norkus, E.; Butkus, E.; Crans, D.C.; Grincienè, G. Deprotonation of $\beta$-cyclodextrin in alkaline solutions. Carbohydr. Res. 2009, 344, 250-254. [CrossRef] [PubMed]

20. Loftsson, T.; Brewster Marcus, E. Cyclodextrins as functional excipients: Methods to enhance complexation efficiency. J. Pharm. Sci. 2012, 101, 3019-3032. [CrossRef] [PubMed]

21. Saha, S.; Roy, A.; Roy, K.; Roy, M.N. Study to explore the mechanism to form inclusion complexes of $\beta$-cyclodextrin with vitamin molecules. Sci. Rep. 2016, 6, 35764. [CrossRef] [PubMed]

22. Coleman, A.W.; Nicolis, I.; Keller, N.; Dalbiez, J.P. Aggregation of cyclodextrins: An explanation of the abnormal solubility of $\beta$-cyclodextrin. J. Incl. Phenom. Mol. Recognit. Chem. 1992, 13, 139-143. [CrossRef]

23. Sabadini, E.; Cosgrove, T.; Egídio, F.D.C. Solubility of cyclomaltooligosaccharides (cyclodextrins) in $\mathrm{H}_{2} \mathrm{O}$ and $\mathrm{D}_{2} \mathrm{O}$ : A comparative study. Carbohydr. Res. 2006, 341, 270-274. [CrossRef] [PubMed]

24. Naidoo, K.J.; Chen, J.Y.-J.; Jansson, J.L.M.; Widmalm, G.; Maliniak, A. Molecular properties related to the anomalous solubility of $\beta$-cyclodextrin. J. Phys. Chem. B 2004, 108, 4236-4238. [CrossRef]

25. Cai, W.; Sun, T.; Shao, X.; Chipot, C. Can the anomalous aqueous solubility of $\beta$-cyclodextrin be explained by its hydration free energy alone? Phys. Chem. Chem. Phys. 2008, 10, 3236-3243. [CrossRef] [PubMed] 
26. Duchěne, D.; Wouessidjewe, D. Pharmaceutical uses of cyclodextrins and derivatives. Drug Dev. Ind. Pharm. 1990, 16, 2487-2499. [CrossRef]

27. Szejtli, J. Highly soluble $\beta$-cyclodextrin derivatives. Starch-Stärke 1984, 36, 429-432. [CrossRef]

28. Loftsson, T.; Duchêne, D. Cyclodextrins and their pharmaceutical applications. Int. J. Pharm. 2007, 329, 1-11. [CrossRef] [PubMed]

29. Davis, M.E.; Brewster, M.E. Cyclodextrin-based pharmaceutics: Past, present and future. Nat. Rev. Drug Discov. 2004, 3, 1023. [CrossRef] [PubMed]

30. Wenz, G. Influence of intramolecular hydrogen bonds on the binding potential of methylated $\beta$-cyclodextrin derivatives. Beilstein J. Org. Chem. 2012, 8, 1890-1895. [CrossRef] [PubMed]

31. Miranda, J.C.D.; Martins, T.E.A.; Veiga, F.; Ferraz, H.G. Cyclodextrins and ternary complexes: Technology to improve solubility of poorly soluble drugs. Braz. J. Pharm. Sci. 2011, 47, 665-681. [CrossRef]

32. Hanna, K.; de Brauer, C.; Germain, P. Cyclodextrin-enhanced solubilization of pentachlorophenol in water. J. Environ. Manag. 2004, 71, 1-8. [CrossRef] [PubMed]

33. Tavornvipas, S.; Arima, H.; Hirayama, F.; Uekama, K.; Ishiguro, T.; Oka, M.; Hamayasu, K.; Hashimoto, H. Some pharmaceutical properties of a new branched cyclodextrin, 6-O- $\alpha-(4-O-\alpha$-D-Glucuronyl)-D-glucosyl $\beta$-cyclodextrin. J. Incl. Phenom. Macrocycl. Chem. 2002, 44, 391-394. [CrossRef]

34. Hirayama, F.; Mieda, S.; Miyamoto, Y.; Arima, H.; Uekama, K. Heptakis(2,6-di-O-methyl-3-O-acetyl)- $\beta$-cyclodextrin: A water-soluble cyclodextrin derivative with low hemolytic activity. J. Pharm. Sci. 1999, 88, 970-975. [CrossRef] [PubMed]

35. Tongiani, S.; Ozeki, T.; Stella, V.J. Sulfobutyl ether-alkyl ether mixed cyclodextrin derivatives with enhanced inclusion ability. J. Pharm. Sci. 2009, 98, 4769-4780. [CrossRef] [PubMed]

36. Fenyvesi, É.; Szemán, J.; Csabai, K.; Malanga, M.; Szente, L. Methyl-beta-cyclodextrins: The role of number and types of substituents in solubilizing power. J. Pharm. Sci. 2014, 103, 1443-1452. [CrossRef] [PubMed]

37. Del Valle, E.M.M. Cyclodextrins and their uses: A review. Process Biochem. 2004, 39, 1033-1046. [CrossRef]

38. Yong, C.W.; Washington, C.; Smith, W. Structural behaviour of 2-hydroxypropyl- $\beta$-cyclodextrin in water: Molecular dynamics simulation studies. Pharm. Res. 2008, 25, 1092-1099. [CrossRef] [PubMed]

39. Terekhova, I.V.; Kumeev, R.S.; Al'per, G.A. The interaction of caffeine with substituted cyclodextrins in water. Russ. J. Phys. Chem. A 2007, 81, 1071-1075. [CrossRef]

40. Müller, B.W.; Brauns, U. Hydroxypropyl- $\beta$ cyclodextrin derivatives: Influence of average degree of substitution on complexing ability and surface activity. J. Pharm. Sci. 1986, 75, 571-572. [CrossRef] [PubMed]

41. Leclercq, L.; Bricout, H.; Tilloy, S.; Monflier, E. Biphasic aqueous organometallic catalysis promoted by cyclodextrins: Can surface tension measurements explain the efficiency of chemically modified cyclodextrins? J. Colloid Interface Sci. 2007, 307, 481-487. [CrossRef] [PubMed]

42. Loftsson, T.; Jarho, P.; Másson, M.; Järvinen, T. Cyclodextrins in drug delivery. Expert Opin. Drug Deliv. 2005, 2, 335-351. [CrossRef] [PubMed]

43. Szente, L.; Fenyvesi, É. Cyclodextrin-lipid complexes: Cavity size matters. Struct. Chem. 2017, $28,479-492$. [CrossRef]

44. Legrand, F.-X.; Sauthier, M.; Flahaut, C.; Hachani, J.; Elfakir, C.; Fourmentin, S.; Tilloy, S.; Monflier, E. Aqueous hydroformylation reaction mediated by randomly methylated $\beta$-cyclodextrin: How substitution degree influences catalytic activity and selectivity. J. Mol. Catal. A Chem. 2009, 303, 72-77. [CrossRef]

45. Azarbayjani, A.F.; Lin, H.; Yap, C.W.; Chan, Y.W.; Chan, S.Y. Surface tension and wettability in transdermal delivery: A study on the in-vitro permeation of haloperidol with cyclodextrin across human epidermis. J. Pharm. Pharmacol. 2010, 62, 770-778. [CrossRef] [PubMed]

46. Kiss, T.; Fenyvesi, F.; Bácskay, I.; Váradi, J.; Fenyvesi, É.; Iványi, R.; Szente, L.; Tósaki, Á.; Vecsernyés, M. Evaluation of the cytotoxicity of $\beta$-cyclodextrin derivatives: Evidence for the role of cholesterol extraction. Eur. J. Pharm. Sci. 2010, 40, 376-380. [CrossRef] [PubMed]

47. Armstrong, D.W.R.; Faulkner, J.; Han, S.M. Use of hydroxypropyl- and hydroxyethyl-derivatized $\beta$-cyclodextrins for the thin-layer chromatographic separation of enantiomers and diastereomers. J. Chromatogr. A 1988, 452, 323-330. [CrossRef] 
48. Francotte, E.; Brandel, L.; Jung, M. Influence of the degree of substitution of cyclodextrin sulfobutyl ether derivatives on enantioselective separations by electrokinetic chromatography. J. Chromatogr. A 1997, 792, 379-384. [CrossRef]

49. Okada, Y.; Matsuda, K.; Hara, K.; Hamayasu, K.; Hashimoto, H.; Koizumi, K. Properties and the inclusion behavior of 6-O- $\alpha$-D-Galactosyl- and 6-O- $\alpha$-D-Mannosyl-cyclodextrins. Chem. Pharm. Bull. 1999, 47, 1564-1568. [CrossRef] [PubMed]

50. Higuchi, T. Physical chemical analysis of percutaneous absorption process from creams and ointments. J. Soc. Cosmet. Chem. 1960, 11, 85-97.

51. Schaefer, H.; Schalla, W.; Zesch, A.; Stüttgen, G. Skin Permeability; Springer: Berlin/Heidelberg, Germany, 1982.

52. Gallaher, D.; Plank, D. $\alpha$-Cyclodextrin as a food ingredient to reduce fat absorption. Agro Food Ind. Hi-Tech 2015, 26, 5-7.

53. Jambhekar, S.S.; Breen, P. Cyclodextrins in pharmaceutical formulations I: Structure and physicochemical properties, formation of complexes, and types of complex. Drug Discov. Today 2016, 21, 356-362. [CrossRef] [PubMed]

54. Loftsson, T.; Magnúsdóttir, A.; Másson, M.; Sigurjónsdóttir, J.F. Self-association and cyclodextrin solubilization of drugs. J. Pharm. Sci. 2002, 91, 2307-2316. [CrossRef] [PubMed]

55. Wang, C.; Wang, X.; Xu, X.; Liu, B.; Xu, X.; Sun, L.; Li, H.; Zhang, J. Simultaneous high-throughput determination of interaction kinetics for drugs and cyclodextrins by high performance affinity chromatography with mass spectrometry detection. Anal. Chim. Acta 2016, 909, 75-83. [CrossRef] [PubMed]

56. Li, H.; Ge, J.; Guo, T.; Yang, S.; He, Z.; York, P.; Sun, L.; Xu, X.; Zhang, J. Determination of the kinetic rate constant of cyclodextrin supramolecular systems by high performance affinity chromatography. J. Chromatogr. A 2013, 1305, 139-148. [CrossRef] [PubMed]

57. Wang, C.; Ge, J.; Zhang, J.; Guo, T.; Chi, L.; He, Z.; Xu, X.; York, P.; Sun, L.; Li, H. Multianalyte determination of the kinetic rate constants of drug-cyclodextrin supermolecules by high performance affinity chromatography. J. Chromatogr. A 2014, 1359, 287-295. [CrossRef] [PubMed]

58. Jansook, P.; Moya-Ortega, M.D.; Loftsson, T. Effect of self-aggregation of $\gamma$-cyclodextrin on drug solubilization. J. Incl. Phenom. Macrocycl. Chem. 2010, 68, 229-236. [CrossRef]

59. Saokham, P.; Loftsson, T. A new approach for quantitative determination of $\gamma$-cyclodextrin in aqueous solutions: Application in aggregate determinations and solubility in hydrocortisone $/ \gamma$-cyclodextrin inclusion complex. J. Pharm. Sci. 2015, 104, 3925-3933. [CrossRef] [PubMed]

60. Saokham, P.; Do, T.T.; Van den Mooter, G.; Loftsson, T. Inclusion complexes of p-hydroxybenzoic acid esters and $\gamma$-cyclodextrin. J. Incl. Phenom. Macrocycl. Chem. 2018, 90, 111-122. [CrossRef]

61. Schönbeck, C.; Madsen, T.L.; Peters, G.H.; Holm, R.; Loftsson, T. Soluble 1:1 complexes and insoluble 3:2 complexes-Understanding the phase-solubility diagram of hydrocortisone and $\gamma$-cyclodextrin. Int. J. Pharm. 2017, 531, 504-511. [CrossRef] [PubMed]

62. Lehner, S.J.; Müller, B.W.; Seydel, J.K. Effect of hydroxypropyl- $\beta$-cyclodextrin on the antimicrobial action of preservatives. J. Pharm. Pharmacol. 1994, 46, 186-191. [CrossRef] [PubMed]

63. Loftsson, T.; Stefánsdóttir, Ó.; Friôriksdóttir, H.; Guômundsson, Ö. Interactions between preservatives and 2-hydroxypropyl- $\beta$-cyclodextrin. Drug Dev. Ind. Pharm. 1992, 18, 1477-1484. [CrossRef]

64. Holm, R.; Olesen, N.E.; Alexandersen, S.D.; Dahlgaard, B.N.; Westh, P.; Mu, H. Thermodynamic investigation of the interaction between cyclodextrins and preservatives-Application and verification in a mathematical model to determine the needed preservative surplus in aqueous cyclodextrin formulations. Eur. J. Pharm. Sci. 2016, 87, 22-29. [CrossRef] [PubMed]

65. Loftsson, T. Increasing the cyclodextrin complexation of drugs and drug biovailability through addition of water-soluble polymers. Pharmazie 1998, 53, 733-740. [PubMed]

66. Jansook, P.; Kurkov, S.V.; Loftsson, T. Cyclodextrins as solubilizers: Formation of complex aggregates. J. Pharm. Sci. 2010, 99, 719-729. [CrossRef] [PubMed]

67. Messner, M.; Kurkov, S.V.; Jansook, P.; Loftsson, T. Self-assembled cyclodextrin aggregates and nanoparticles. Int. J. Pharm. 2010, 387, 199-208. [CrossRef] [PubMed]

68. Loftsson, T.; Hreinsdóttir, D.; Másson, M. Evaluation of cyclodextrin solubilization of drugs. Int. J. Pharm. 2005, 302, 18-28. [CrossRef] [PubMed] 
69. Savolainen, J.; Järvinen, K.; Taipale, H.; Jarho, P.; Loftsson, T.; Järvinen, T. Coadministration of a water-soluble polymer increases the usefulness of cyclodextrins in solid oral dosage forms. In Proceedings of the Ninth International Symposium on Cyclodextrins, Dordrecht, The Netherlands, 31 May-3 June 1998; pp. 261-264.

70. Jansook, P.; Loftsson, T. CDs as solubilizers: Effects of excipients and competing drugs. Int. J. Pharm. 2009, 379, 32-40. [CrossRef] [PubMed]

71. Kim, Y.; Oksanen, D.A.; Massefski, J.W.; Blake, J.F.; Duffy, E.M.; Chrunyk, B. Inclusion complexation of ziprasidone mesylate with $\beta$-cyclodextrin sulfobutyl ether. J. Pharm. Sci. 1998, 87, 1560-1567. [CrossRef] [PubMed]

72. Omari, M.M.A.; Zughul, M.B.; Davies, J.E.D.; Badwan, A.A. Factors contributing to solubility synergism of some basic drugs with $\beta$-cyclodextrin in ternary molecular complexes. J. Incl. Phenom. Macrocycl. Chem. 2006, 54, 159-164. [CrossRef]

73. Loftsson, T.; Matthíasson, K.; Másson, M. The effects of organic salts on the cyclodextrin solubilization of drugs. Int. J. Pharm. 2003, 262, 101-107. [CrossRef]

74. He, Y.; Li, P.; Yalkowsky, S.H. Solubilization of fluasterone in cosolvent/cyclodextrin combinations. Int. J. Pharm. 2003, 264, 25-34. [CrossRef]

75. Soltani, N.; Shaynafar, A.; Djozan, D.; Jouyban, A. Solubility of three basic drugs in propylene glycol + water mixtures in the presence of $\beta$-cyclodextrin. J. Drug Deliv. Sci. Technol. 2013, 23, 187-190. [CrossRef]

76. Müller, B.W.; Albers, E. Effect of hydrotropic substances on the complexation of sparingly soluble drugs with cyclodextrin dervatives and the influence of cyclodextrin complexation on the pharmacokinetics of the drugs. J. Pharm. Sci. 1991, 80, 599-604. [CrossRef] [PubMed]

77. Loftsson, T.; Sigurðardóttir, A.M. The effect of polyvinylpyrrolidone and hydroxypropyl methylcellulose on HP $\beta C D$ complexation of hydrocortisone and its permeability through hairless mouse skin. Eur. J. Pharm. Sci. 1994, 2, 297-301. [CrossRef]

78. Loftsson, T.; Frikdriksdóttir, H.; Sigurkdardóttir, A.M.; Ueda, H. The effect of water-soluble polymers on drug-cyclodextrin complexation. Int. J. Pharm. 1994, 110, 169-177. [CrossRef]

79. Loftsson, T.; Másson, M. The effects of water-soluble polymers on cyclodextrins and cyclodextrin solubilization of drugs. J. Drug Deliv. Sci. Technol. 2004, 14, 35-43. [CrossRef]

80. Yamakawa, T.; Nishimura, S. Liquid formulation of a novel non-fluorinated topical quinolone, T-3912, utilizing the synergic solubilizing effect of the combined use of magnesium ions and hydroxypropyl- $\beta$-cyclodextrin. J. Control. Release 2003, 86, 101-113. [CrossRef] 